Article

\title{
Simulation of Distributed Generation with Photovoltaic Microgrids-Case Study in Brazil
}

\section{Gustavo Azevedo Xavier ${ }^{1, \dagger}$, Delly Oliveira Filho ${ }^{1, \dagger, *}$, José Helvecio Martins ${ }^{1, \dagger}$, Paulo Marcos de Barros Monteiro ${ }^{2, \dagger}$ and Antônia Sônia Alves Cardozo Diniz ${ }^{3, \dagger}$}

1 Department of Agricultural Engineering, Universidade Federal de Vicosa, Av. P.H. Rolfs s/n, 36570-000 Vicosa, MG, Brazil; E-Mails: gustavo.xavier@ufv.br (G.A.X.); j.helvecio.martins@gmail.com (J.H.M.)

2 Department of Control and Automation, Universidade Federal de Ouro Preto, Escola de Minas, Campus Morro do Cruzeiro, 35400-000 Ouro Preto, MG, Brazil; E-Mail: paulo@em.ufop.br

3 Department of Mechanical Engineering, Pontificia Universidade Catolica de Minas Gerais, Av. Dom Jose Gaspar, 500, Coração Eucarístico, 30535-901 Belo Horizonte, MG, Brazil; E-Mail: asacd@pucminas.br

$\dagger$ These authors contributed equally to this work.

* Author to whom correspondence should be addressed; E-Mail: delly@ufv.br; Tel.: +55-31-3899-1897.

Academic Editor: Josep M. Guerrero

Received: 2 March 2015 / Accepted: 24 April 2015 / Published: 7 May 2015

Abstract: Elevated prices and lack of proper legislation and government incentives have been the main barriers in the development of the photovoltaic market in Brazil. In an attempt to overcome those barriers, a microgrid model was proposed and simulated. In the proposed microgrids, residential consumers are connected to each other to maximize the investment return by trading the surplus of generated energy among them. Different topologies and scenarios were studied from electrical energy and economic standpoints. Stochastic data of solar radiation were simulated for the city of Viçosa, Minas Gerais, Brazil, for the period of one year, considering the statistical behavior of a series over 20 years. The system output power and energy balance were calculated considering a model for photovoltaic generators and the radiation simulated data. By determining the generated energy and electrical needs of the microgrid members, the cash flow and economic feasibility were calculated. Sensitivity analyses were performed by varying economic parameters to determine situations where investment becomes feasible. This paper 
shows that microgrid contributes to improve the economics and the initial investments. The number of participants in a microgrid, the electricity and the equipment costs are important parameters to speed up the economic and technical feasibility process.

Keywords: photovoltaic feasibility; flexible generation; distributed energy resources

\section{Introduction}

Worldwide, there is a predominance of power generation in centralized systems, usually from large fossil fuel or nuclear power plants. The development of small-unit power generating systems and changes that have occurred in power system operation and regulation have created opportunities for consumers to generate their own power [1].

In Brazil, most electricity generation is hydroelectric. Because of the size of the country, a long transmission system is required to carry this energy to consumer centers. Power rationing that occurred in 2001 showed the fragility of the generation system in Brazil, strengthening the discussions on alternative energy sources [2]. These factors show the importance of diversifying energy sources through Distributed Generation (DG). A significant change is foreseen for the current structure of highly centralized, large capacity power plants. A new structure, with the highly decentralized insertion of small- and medium-capacity power units, is expected [3].

Regarding the use of renewable energy, Brazil is one of the most advanced countries in South America [4]. Data from the National Energy Balance 2011 show that the primary energy on the Brazilian matrix is composed by $45.5 \%$ renewable energy (hydraulic, firewood, charcoal, sugarcane and other renewable sources, such as agricultural residues) [5]. Figure 1 shows the distribution of the sources of primary power generation in Brazil. It should be highlighted that the percentage of useful energy consumed in Brazil obtained from renewable sources should be even greater because much of Brazilian renewable energy is hydroelectric. Moreover, power conversion efficiency, from electrical energy to final end use, is usually higher compared to other energy sources. Thus, the percentage of useful energy from renewable sources tends to be higher than the $45.5 \%$ mentioned.

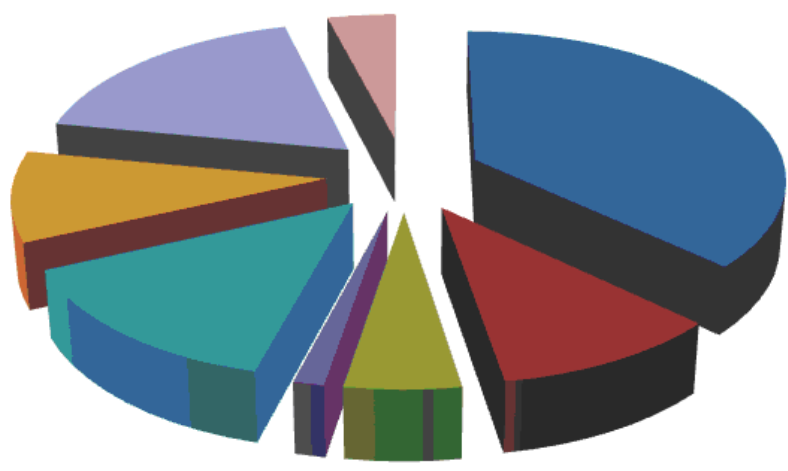

\footnotetext{
- Petroleum and byproducts - $36.7 \%$

- Natural gas - $10.3 \%$

- Coal and coke - $5.2 \%$

- Nuclear - $1.4 \%$

- Hydraulic - $14.0 \%$

- Firewood and charcoal $-9.7 \%$

- Sugar cane - $17.8 \%$

Other renewable sources $-4.0 \%$
}

Figure 1. Primary energy production in Brazil in 2010 [5].

The analysis of electricity generation alone is shown in Figure 2 and reveals that $74.3 \%$ comes from hydro sources. Furthermore, imported electrical energy is also hydroelectricity; thus, it can be stated 
that over $80 \%$ of the electricity used in Brazil is renewable [5]. These figures contrast strongly with the World's electrical energy consumption because renewable sources account for approximately $20.9 \%$ of the electricity generation.
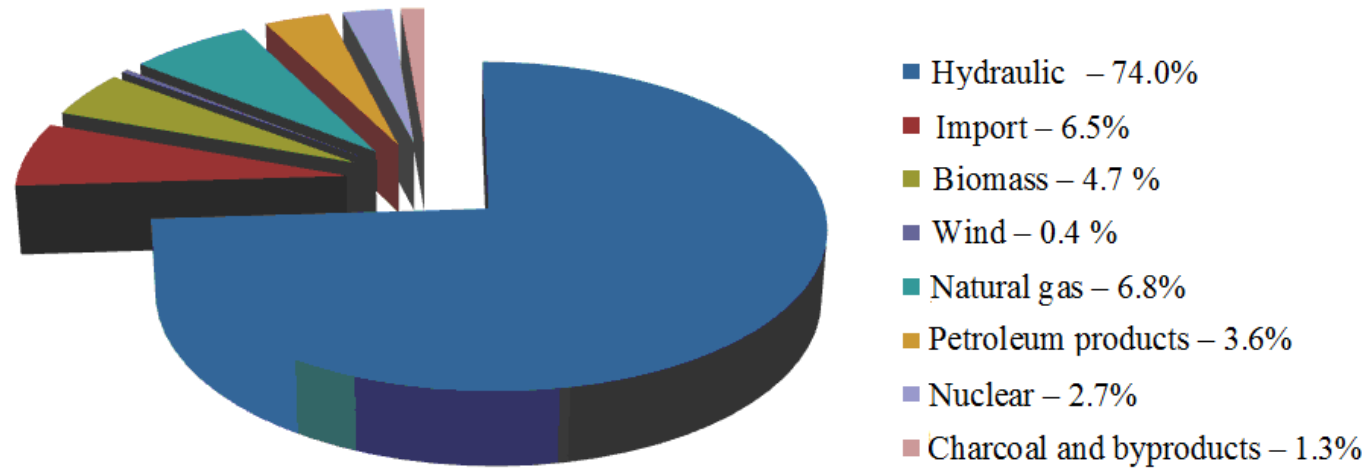

Figure 2. Domestic supply of electricity in Brazil in 2010 [5].

The use of microgrids powered by photovoltaic systems and other alternative energy sources can contribute significantly to world energy demand, gradually replacing the plants that generate electricity using coal, petroleum and nuclear power. The most important alternative sources include micro-turbines, photovoltaics, fuel cells and internal combustion engines using biofuels, such as ethanol, biodiesel and biogas. These emerging technologies have lower emissions and the potential for lower costs in the medium term. Some countries and organizations have invested in researching microgrids, and much remains to be done for the microgrids to be placed on the market $[6,7]$.

Because of its location, Brazil has excellent solar radiation levels. This feature is an advantage over industrialized countries regarding the use of solar photovoltaic energy [8-10]. The Brazilian Government created the Incentive Program for Alternative Energy Sources (PROINFA) to diversify its energy sources based on the principle that distributed generation systems can provide a fast, modular, and decentralized solution to expand the capacity of power generation and increase reliability. Under the coordination of the Ministry of Mines and Energy, the program was set to acquire $3300 \mathrm{MW}$ of electrical power in the Integrated National System to be produced by wind, biomass and small hydropower (SHP) by the year 2008 and supply approximately $10 \%$ of the consumption in 20 years.

The latest breakthrough for distributed generation in Brazil occurred on 17 April 2012 with the approval of Resolution 482 by the National Electric Energy Regulatory Agency (ANEEL), which allows consumers to install small generation units on their sites to become energy independent. Feed-in tariffs were not allowed by the Brazilian law. It should be emphasized that the operation of microgrids, connected to or disconnected from the power system, remains forbidden.

Although Brazil has high levels of solar radiation, the lack of incentives and the elevated costs of photovoltaic systems have been a barrier to the development of the PV market in Brazil. To promote the feasibility of PV systems, a microgrid model that increases the earnings from generated electricity was proposed. The present study aimed to simulate and analyze the operation of microgrids connected to the electric power system with photovoltaic generation and energy storage in batteries.

This article is divided in four sections: Section 1 is an introduction to the matter and the importance of this subject. Section 2 describes the methodology applied. Section 3 provides the results and analysis, and Section 4 presents the final considerations about the research. 


\section{Methodology}

\subsection{Radiation Data}

The methodology developed by Cabral et al. [11] was used to simulate the radiation data used in this study. Radiation data were evaluated by a stochastic method, using monthly average daily global radiation values derived from a typical meteorological year over a period of 20 years to generate hourly data to be used in the simulation. In this methodology, the following parameters were estimated: (I) the hourly global radiation on a inclined surface; (II) the hourly global radiation on a horizontal surface; (III) the daily global radiation on a horizontal surface; (IV) the hourly diffuse radiation on a horizontal surface calculated from hourly global radiation and extraterrestrial hourly radiation; (V) the hourly sky diffuse radiation based on an anisotropic model; and (VI) the hourly ground reflected diffuse radiation based on anisotropic reflection model. Markov transition matrices were used to estimate the daily clearness index based on historic data from meteorological stations. It was possible to describe the radiation data by a stochastical model improving the estimation of the electrical output power from the photovoltaic modules.

The one-diode-equivalent model was used for the simulation of photovoltaic generators [11]. The output power of a photovoltaic generator was calculated considering a system with a maximum power transfer tracker.

\subsection{Battery Model}

Battery set sizing depends only on battery rated capacity, voltage and the desired autonomy. For the photovoltaic system simulation, the batteries were considered to be initially fully charged, and the total stored energy (Wh) was obtained by multiplying the battery capacity (Ah) by its rated voltage (V). The efficiencies of battery charge and battery discharge were considered to be $70 \%$ and $90 \%$, respectively, according to the data obtained by [11].

\subsection{Loads Characterization}

The electrical load considered was a set of residences. For each residence, the load was considered to be the sum of lights and electrical appliances. The average power values for the daily and weekly pattern of use of the electrical residential load commonly used in Brazil were considered to be the ones described by PROCEL [12].

The load curves were obtained from the adapted stochastic method proposed by Souza et al. [13]. For each load, the amount of usage time was simulated during the day, stochastically, by considering the following: (I) the random, daily average usage time variation; and (II) the random, time of day use variation.

The variation allowed in the load pattern was controlled by the algorithm. The first step was to determine the daily amount of usage time for each load for any given day. The second step was to determine the most likely period of usage for each load. For this purpose, probability curves were generated for each load according to usage patterns of the Brazilian middle class. These curves show the chances for the loads to be used at a particular time of day on a particular weekday. The third step was to 
estimate the number of times that the load is used throughout the day. The developed algorithm simulates the load probability curves using the value determined by [12] in 2011 as the average and a deviation around a range bounded by minimum and maximum limits.

\subsection{Photovoltaic System Sizing}

The methodology used for PV system sizing for each residential consumer was in accordance with the spreadsheets presented by Reference Center for Solar and Wind Energy (CRESESB) [14], originally produced by Sandia National Laboratories for the manual titled "Stand-Alone Photovoltaic Systems-A Handbook of Recommended Design Practices" [15] and adapted for Brazil. Spreadsheets were developed for fixed isolated systems without solar concentrators. Instructions for completion are found in this manual and in [11]. The spreadsheets provide a deterministic method to calculate the PV system, including the energy storage, based on load and radiation data and using analytical equations to predict operation of the photovoltaic systems. The storage systems size were obtained considering a consecutive number of days in which the demand can be met relying only on the storage system.

\subsection{Topologies}

The microgrid model presented in this study proposes that residential consumers are interconnected, forming a group in which some homes have photovoltaic generation and energy storage in batteries, while others do not. Thus, the surplus of energy generated by those with photovoltaic systems could be used by those without as an alternative to a local electrical utility. The photovoltaic systems were sized to supply consumers isolated from the network. The proposed microgrid should be connected to the power system. A schematic model of the proposed microgrid is shown in Figure 3.

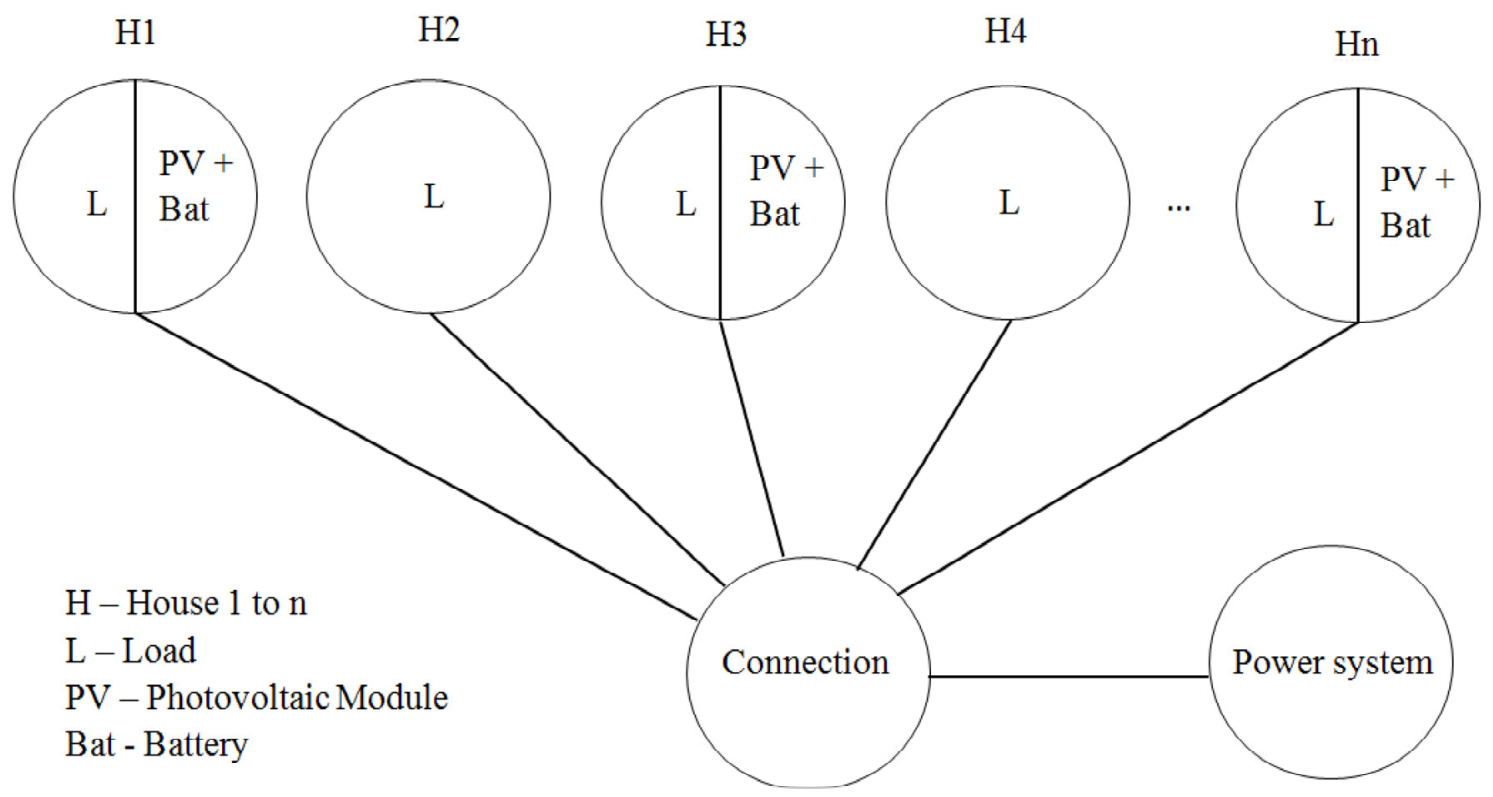

Figure 3. Schematic drawing of the proposed microgrid.

An initial analysis was performed to determine the economic feasibility as function of the number of participants in the microgrid. The simulations were performed varying the size of the microgrid from eleven to sixty members. It was done considering a fixed number of ten microgrid participants 
with photovoltaic systems which are connected among themselves to a variable number of microgrid participants without photovoltaic generation ranging from one to fifty. The number of microgrid participants was limited to sixty because the larger the microgrid, the bigger the loss of energy and the complexity of both the management and the distribution system inside the microgrid. The Net Present Value (NPV) and the Internal Return Rate (IRR) were obtained for each case to verify which arrangements make the proposed microgid economically feasible. Thereafter, the photovoltaic systems that were originally sized to supply individual consumers were studied in three different microgrid arrangements, in an effort to obtain the necessary conditions to the economic feasibility: (I) twenty residential customers connected to each other, ten of which have photovoltaic systems installed; (II) forty residential customers connected to each other, ten of which have photovoltaic systems installed; and (III) ten residential customers with photovoltaic generation connected to a commercial or industrial consumer capable of using all generated energy surplus. These arrangements were chosen between the previous fifty cases analyzed to: (I) provide a scenario with high penetration level of photovoltaic generation within a group; (II) provide a scenario with low penetration level of photovoltaic generation within a group; and (III) provide a scenario where all the energy generated by the photovoltaic modules would be consumed by the microgrid members.

The internal and external microgrid power flow was assessed using knowledge of the following: (I) the amount of energy generated by the photovoltaic generators at each moment; (II) energy and power demand; and (III) state of battery charge. The power flow analysis calculates both the individual energy consumption and the microgrid energy balance.

\subsection{Energy Balance}

The simulated microgrid had consumers with and without the following attributes: (I) photovoltaic generation; (II) energy storage capability; and (III) connection to the grid. The energy balance was calculated for the different topologies studied by the following evaluations:

(I) The solar radiation at the photovoltaic generators;

(II) The electrical energy generated;

(III) The battery state of charge (SOC), defined as the percentage of the nominal storage capacity available, which depends on:

a. The initial state of the batteries;

b. The energy supplied by the photovoltaic generators;

c. The energy sent by the batteries to the load;

(IV) For each individual consumer:

a. The load curve and the electrical demand;

b. The energy consumed from the grid;

c. The energy consumed from the photovoltaic generation modules.

The developed algorithm calculates the energy generated at the photovoltaic modules and the consumers' needs at 10 min intervals. The energy balance algorithm flowchart is shown in Figure 4. 
The radiation data for a typical year were available on a per hour basis. A polynomial interpolation of the hourly radiation data was carried out to obtain a 10-min basis. The load data were also generated on a 10-min basis. Thus, the energy balance could be performed over a shorter time interval.

After the energy balance was evaluated, economic aspects were also appraised to account for the individual consumer and microgrid perspectives.

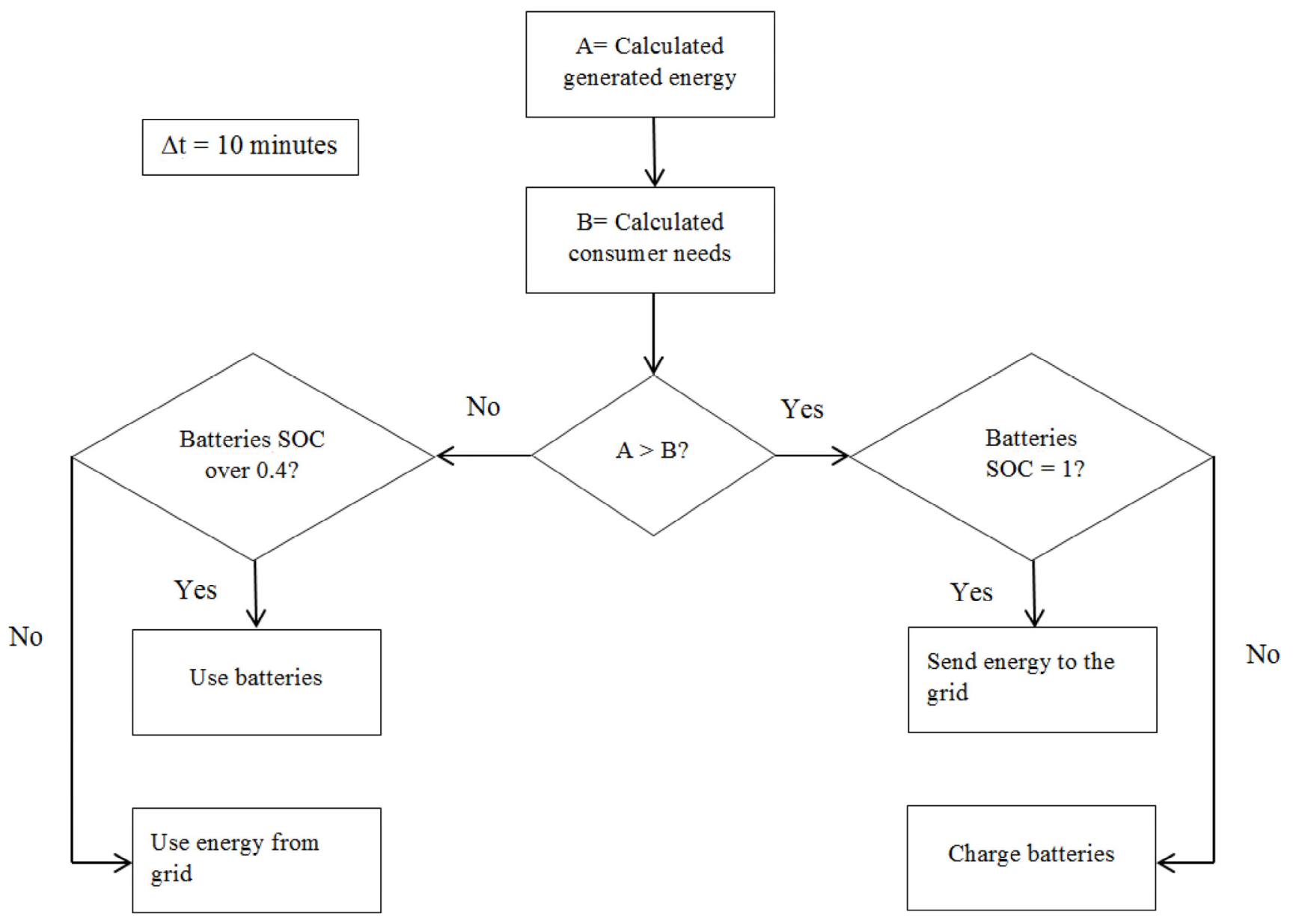

Figure 4. Energy balance algorithm flowchart.

\subsection{Microgrid Economic Aspects}

The economic analysis considered a planning horizon of 25 years and verified the investment feasibility by accounting for revenues and expenditures with microgrid implementation for some customers using photovoltaic generators and energy storage. The internal return rate and the net present value were calculated as indicators of microgrid feasibility.

The following aspects were considered for the simulations: (I) the amount paid by the utility to each photovoltaic owner for excess energy generated in the microgrid; (II) the amount saved by each photovoltaic owner by not using energy from the utility; and (III) the amount paid by each microgrid participant without a PV system to the owners of PV systems. In case (I), a value was estimated for the price of $1 \mathrm{kWh}$ to be sold to the utility because until this study be completed the proposed commercialization has not yet occurred in Brazil. Micro hydro-power plants are paid a low price for generated energy thus, the value considered was $\$ 0.15 / \mathrm{kWh}$, that is half of the retail energy price. 
In case (II), the current value charged by the local utility, CEMIG, was used, which was, at the time of this work, $\$ 0.30 / \mathrm{kWh}$. For case (III), a value of $\$ 0.22 / \mathrm{kWh}$ was considered, which was the average of the figures for cases (I) and (II) and may thus provide benefits to all microgrid participants.

The parameters for economic analysis considered are shown in Table 1. The opportunity cost was considered to be the savings account earnings after discounting the inflation. The financial return obtained with the microgrid was compared to that obtained in the absence of interconnection to other consumers. Sensitivity analyses were performed, varying only one economic parameter per instance for each topology studied. The effects of variation in the cost of acquisition and installation of the system, increase in energy prices above inflation and opportunity cost were analyzed.

Table 1. Parameters for economic analysis.

\begin{tabular}{ccc}
\hline Parameters & Value & Unit \\
\hline Interest/opportunity cost & 1.57 & $\% /$ year \\
Increase in energy price above inflation & 3 & $\% /$ year \\
Planning horizon & 25 & Year \\
Maintenance & 0.50 & $\% /$ year \\
Battery life & 10 & Year \\
Electricity rate supplied by the utility & 0.300 & $\$ / \mathrm{kWh}$ \\
Energy sold by the microgrid to the members & 0.225 & $\$ / \mathrm{kWh}$ \\
Energy sold by the microgrid to the utility & 0.150 & $\$ / \mathrm{kWh}$ \\
\hline
\end{tabular}

Other analyses related to the gain that could be obtained indirectly with the use of photovoltaic systems were also performed. The supply of energy at peak hours, non-guaranteed access to energy and new possibilities arising from the start of the energy certification of buildings in Brazil could significantly contribute to the growth of the photovoltaic market in the country. The impact of having no energy storage was also analyzed for the three topologies studied.

\section{Results and Discussion}

The results are organized by subsections. In the first subsection the PV system sizing results are presented to show the generated energy by one PV system. The second subsection show the results of load characterization. Sections 3.3-3.6 show the results of three different topologies of microgrids. Sections 3.7-3.10 show the economic analysis and sensibility analysis. Sections 3.11-3.14 show other possibilities, related to legislation that may contribute to the feasibility of the microgrid topologies proposed.

\subsection{PV System Sizing}

The loads for the photovoltaic system sizing for a typical Brazilian residence with three dwellings are presented in Table 2.

The bank of batteries was designed to ensure autonomy for three days. Table 3 presents the characteristics of the batteries selected, according to the manufacturer's datasheet, and the results of the dimensioning of the storage system. 
Table 2. Loads for sizing photovoltaic system for a typical residence.

\begin{tabular}{ccccc}
\hline Equipment & Quantity & Power $(\mathbf{W})$ & Monthly Use (day/month) & Daily Use (h/day) \\
\hline $20 "$ TV & 1 & 90 & 30 & 5 \\
Shower & 1 & 3500 & 30 & 0.66 \\
Stereo system & 1 & 20 & 12 & 1 \\
DVD & 1 & 10 & 8 & 2 \\
Lamp & 7 & 20 & 30 & 7 \\
Computer & 1 & 180 & 20 & 3 \\
Fan & 2 & 50 & 30 & 8 \\
Refrigerator & 1 & 90 & 30 & 12 \\
Hair dryer & 1 & 1400 & 4 & 0.1 \\
Electric iron & 1 & 1000 & 4 & 1 \\
Washing machine & 1 & 500 & 4 & 1 \\
\hline
\end{tabular}

Table 3. Description and characterization of batteries.

\begin{tabular}{cc}
\hline Description & Characterization \\
\hline Type & Lead-acid \\
Rated voltage & $12 \mathrm{~V}$ \\
Rated capacity & $220 \mathrm{Ah}$ \\
Maximum depth of discharge & 0.6 \\
Number of batteries & 8 \\
Storage capacity & $880 \mathrm{Ah}$ \\
Useful capacity & $528 \mathrm{Ah}$ \\
\hline
\end{tabular}

System sizing was performed considering an $80 \mathrm{~W}$ photovoltaic module, Table 4.

Table 4. Characteristics of the $80 \mathrm{~W}$ PV generator.

\begin{tabular}{cc}
\hline Description & Characterization \\
\hline Rated voltage & $12 \mathrm{~V}$ \\
Voltage at maximum power & $17.29 \mathrm{~V}$ \\
Open circuit voltage & $21.6 \mathrm{~V}$ \\
Current at maximum power & $4.37 \mathrm{~A}$ \\
Short circuit current & $4.72 \mathrm{~A}$ \\
Rated power & $75.56 \mathrm{~W}$ \\
\hline
\end{tabular}

The PV system dimensioning results for typical Brazilian residences are presented in Table 5.

Table 5. Generator sizing.

\begin{tabular}{cc}
\hline Description & Characterization \\
\hline Number of modules in parallel & 11 \\
Number of modules in series & 2 \\
Total of modules & 22 \\
Rated current in the arrangement & $48.07 \mathrm{~A}$ \\
Short-circuit current in the arrangement & $51.92 \mathrm{~A}$ \\
Rated voltage of the arrangement & $34.58 \mathrm{~V}$ \\
\hline
\end{tabular}


The instantaneous power generated was calculated at intervals of one hour, knowing the total number of modules required to supply power to the load. The result is shown in Figure 5.

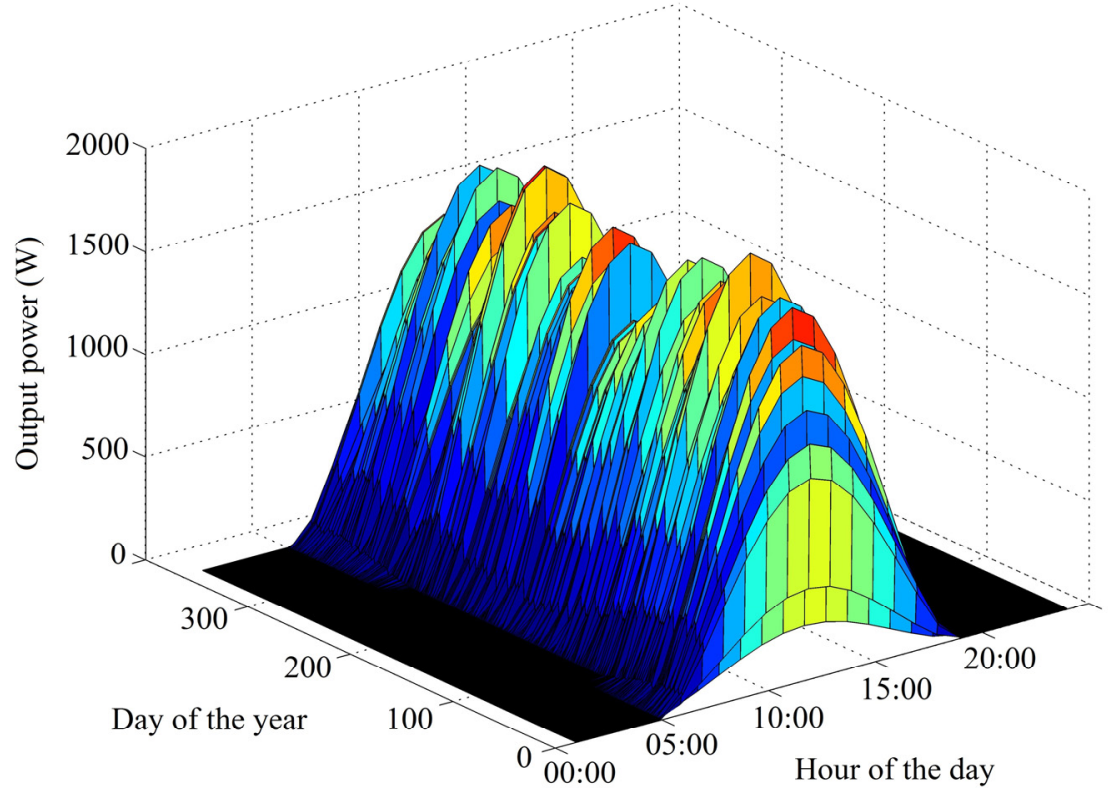

Figure 5. Generated power simulated according to the solar radiation and ambient temperature for Viçosa, MG, Brazil.

\subsection{Loads}

Figure 6 shows the output of the load curves generator program for any given day. It is important to note that the software system generates a different load curve for each day, considering both the load characteristics and the stochastic aspects.

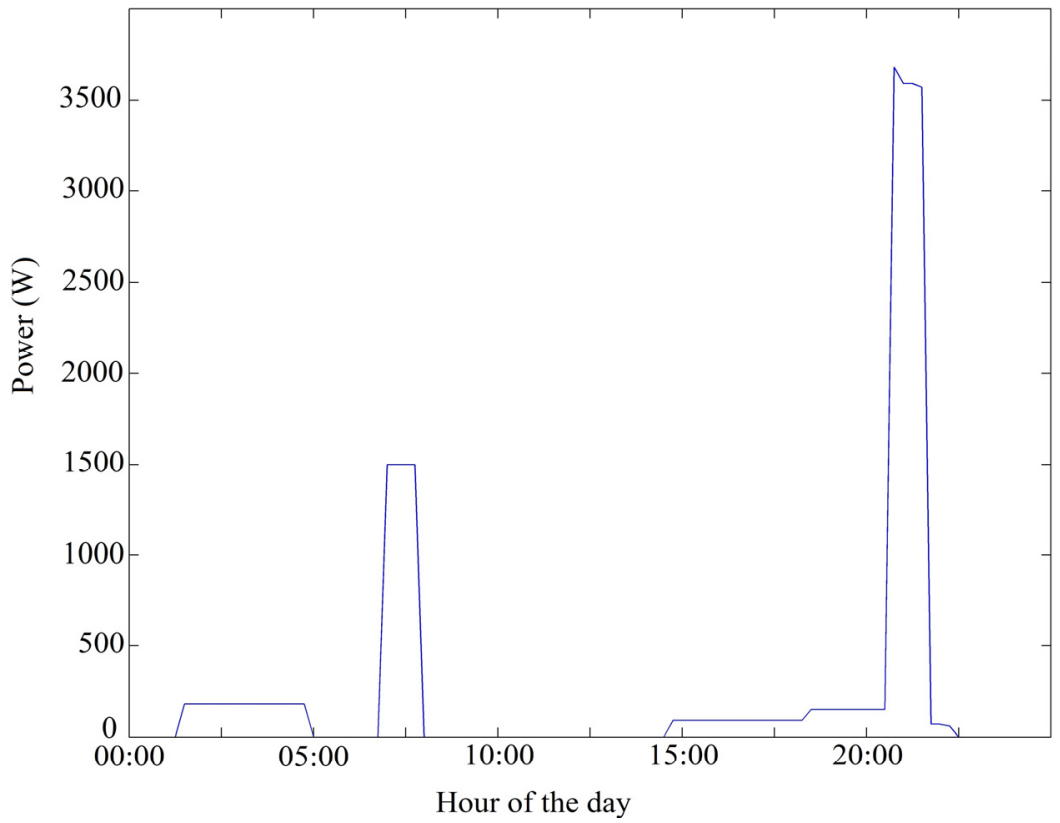

Figure 6. Estimated load curve of a residence for a day. 


\subsection{Initial Analyses}

The initial analyses were performed to obtain the results of economic feasibility to the proposed microgrid for fifty different arrangements, as described in Section 2.5. The NPV and IRR results are shown in Figure 7.

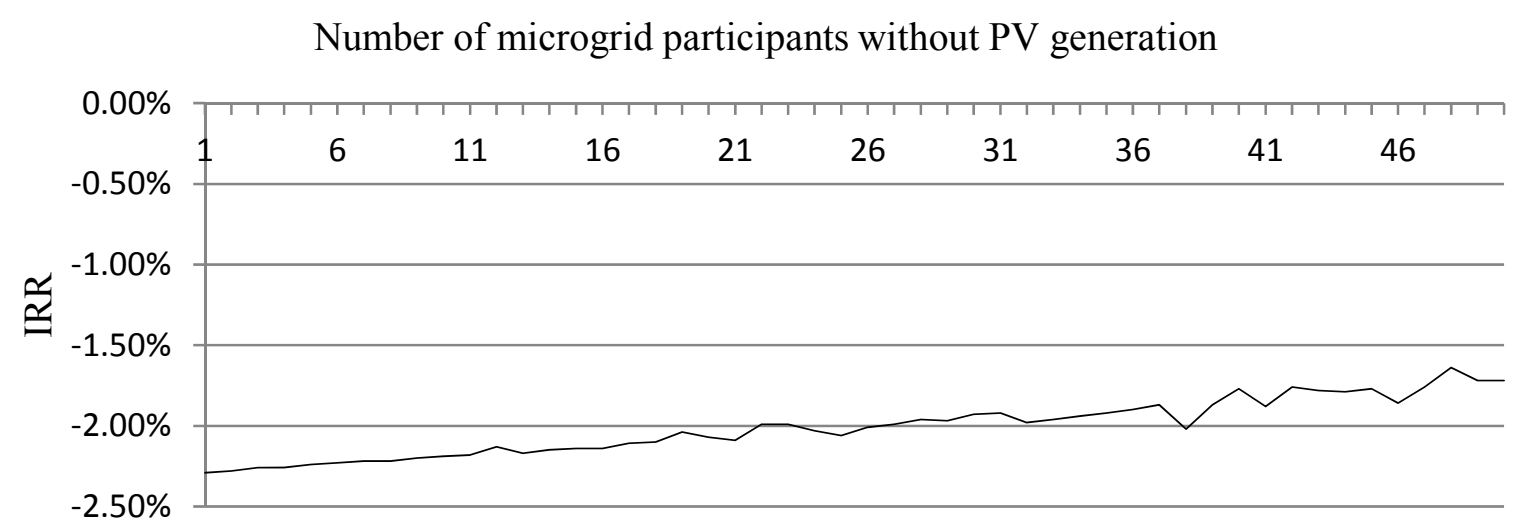

Number of microgrid participants without PV generation

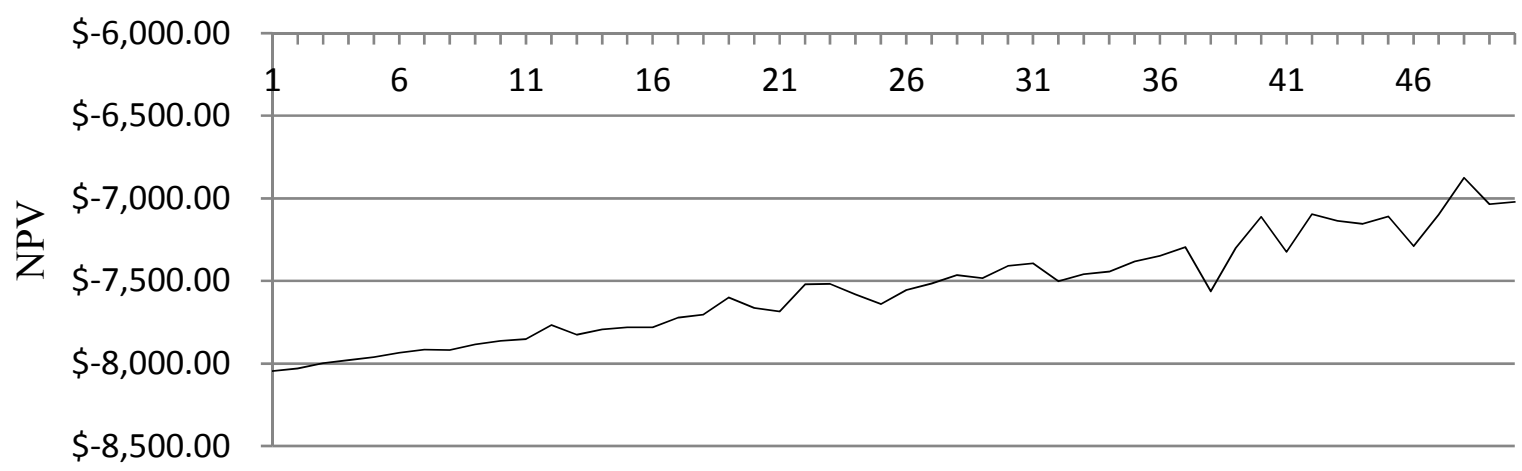

Figure 7. NPV and IRR for fifty arrangements of the proposed microgrid.

The results show that increasing the number of microgrid participants without photovoltaic generation improves the economic feasibility of the system, although the feasibility has not been accomplished by varying this number from one to fifty. The graphics suggest a tendency of improve the economic aspect by raising the number of microgrid participants, but the size of the microgrid may imply in major energy losses between the microgrid members. The NPV was improved in approximately $\$ 1,000.00$ by varying the number of microgrid members from 11 to 60 . By a simple extrapolation of these results, we can conclude that, for the system proposed, a microgrid with approximately 400 members, that is eight times greater than the system studied in this paper, would reach feasibility. The authors are aware of the need of further analyses since simple extrapolation may result in conclusions that not necessarily reflect the behavior of a power system.

\subsection{Topology 1}

The total surplus energy used by the 10 homes without PV systems and energy storage for one year was $1,099.90 \mathrm{kWh}$, with a monthly average equal to $91.65 \mathrm{kWh}$. Each of the ten homes used, 
on average, $9.17 \mathrm{kWh}$ of the energy surplus available in a month from the microgrid. The total energy provided by the PV systems to the microgrid in the simulated year was $14,374.3 \mathrm{kWh}$.

After calculating the amount of network surplus energy used by the 10 homes without PV generation, the amount of excess energy leftover from the original amount was assessed. The result is shown in Figure 8.

The total remaining for the year was $5776.00 \mathrm{kWh}$. According to the simulation results, only $16.00 \%$ of the total energy available was used in the microgrid. This result was observed because of the load characteristic studied and the time period when there is more energy available.

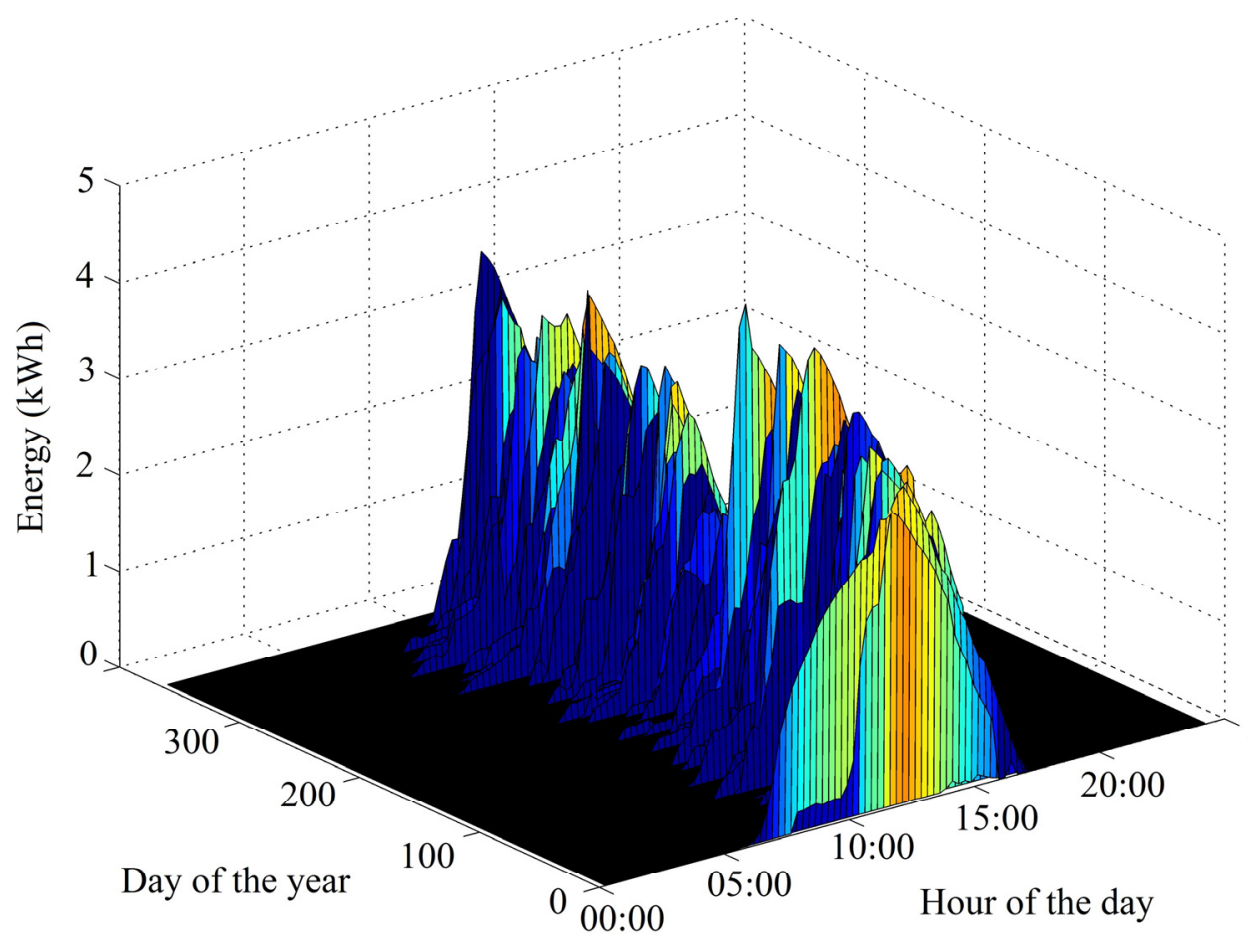

Figure 8. Photovoltaic energy not consumed on the microgrid for topology 1.

\subsection{Topology 2}

Thirty homes were tested for a year, and the total surplus energy used in these homes was $2708.50 \mathrm{kWh}$, with a monthly average equal to $225.71 \mathrm{kWh}$. Each of the thirty residences used, on average, $7.52 \mathrm{kWh}$ of the total power available over a month. The total energy provided by the PV systems to the microgrid in the simulated year was $15,982.4 \mathrm{kWh}$.

After calculating the amount of surplus energy in the grid for the 30 homes without PV generation, the amount of energy remaining was calculated. The result is shown in Figure 9.

The total energy remaining over a year was $4167.4 \mathrm{kWh}$. In this second case, $39.39 \%$ of the energy surplus was used in the microgrid. 


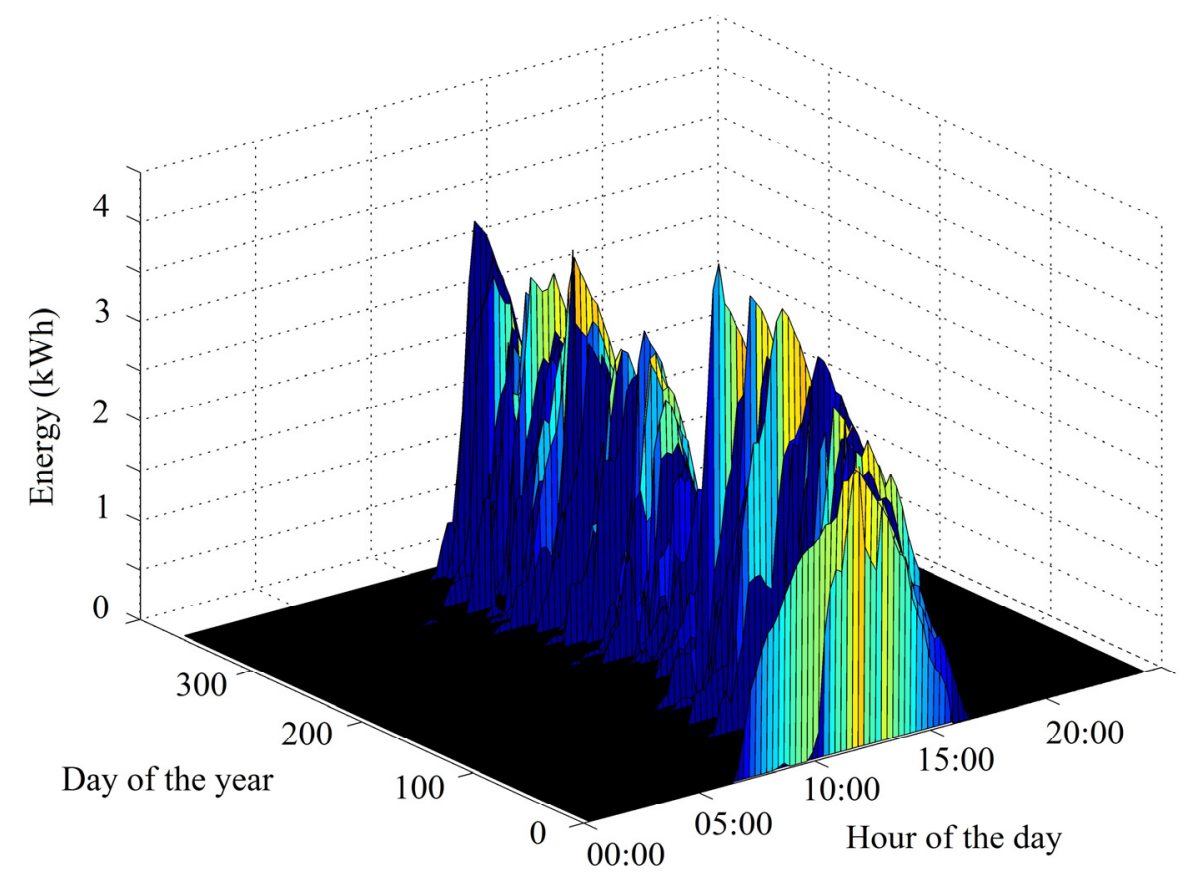

Figure 9. Photovoltaic energy not consumed on the microgrid for topology 2.

\subsection{Topology 3}

The case of a group of houses with photovoltaic generators connected to the grid, in which there was a consumer whose load curve allowed the use of all surplus energy in the microgrid, was studied to maximize the economic gain from the energy sold. The same group of ten owners of photovoltaic systems evaluated for topologies 1 and 2 was considered. The total surplus energy was $6875.9 \mathrm{kWh}$ per year, which corresponds to a monthly average generation of $572.98 \mathrm{kWh}$. The total energy provided by the PV systems to the microgrid in the simulated year was $20,150.3 \mathrm{kWh}$.

\subsection{Economic Analyses}

The economic analysis was performed from the perspective of PV system owners. A price quote for a residential PV system with energy storage was carried out. The values are shown in Table 6. The PV generators account for $73.57 \%$ of the total initial investment. In a similar study performed by [16], the cost of the PV generators accounts for $45 \%$ of the system costs in Italy; this result shows the high costs in Brazil. Batteries account for $18.28 \%$ of the initial investment, but, as they have a shorter life span, they must be replaced more frequently. The cost per $W_{\text {peak }}$ for this system is $\$ 10.20$. It should be noted that the price per $W_{\text {peak }}$ in Brazil is equal to the worst case among the European countries mentioned by [17]. The results found by [18] show that the photovoltaic system becomes feasible if its price is under $\$ 6.00$ per $W_{\text {peak }}$ in Japan. 
Table 6. PV system with energy storage installation cost for one residence.

\begin{tabular}{ccccc}
\hline \multirow{2}{*}{ Equipment } & \multirow{2}{*}{ Price (\$) } & \multirow{2}{*}{ Quantity } & \multicolumn{2}{c}{ Total } \\
\cline { 4 - 5 } & & 22 & $13,200.00$ & 73.57 \\
\hline Photovoltaic Module 80 W & 600.00 & 8 & $3,280.00$ & 18.28 \\
Battery 12 V 220 Ah & 410.00 & 1 & 652.00 & 3.63 \\
Frequency Inverter 2 kW & 652.00 & 1 & 559.00 & 3.12 \\
Charge controller & 559.00 & 1 & 250.00 & 1.40 \\
Cables, connectors, meters, etc. & 250.00 & & $17,941.00$ & 100.00 \\
\hline Total & & & &
\end{tabular}

Table 7 lists the values received during one year by members of the group in the microgrid that have photovoltaic generation systems with energy storage as a result of several activities: energy trading in the microgrid, energy selling to the electric utility and energy bill savings. There is some criticism of the energy assumed values. As previously shown in Table 1, the energy costs were considered to be $100 \%$, $75 \%$ and $50 \%$ of the energy tariff for residential consumers, the value to be paid by the microgrid member to the owner and the value to be paid by the utility to the owner of PV system, respectively.

Table 7. Energy and economic aspects of microgrid Topologies 1, 2 and 3.

\begin{tabular}{|c|c|c|c|c|}
\hline \multirow{2}{*}{ Description } & \multirow{2}{*}{ Unit } & \multicolumn{3}{|c|}{ Microgrid } \\
\hline & & Topology 1 & Topology 2 & Topology 3 \\
\hline Electricity sold within the microgrid & $(\mathrm{kWh} /$ year) & $1,099.90$ & $2,708.50$ & $6,875.90$ \\
\hline Amount received from members of the microgrid & (\$/year) & 247.48 & 640.91 & $1,547.07$ \\
\hline Energy sold to the utility & $(\mathrm{kWh} /$ year) & $5,776.00$ & $4,167.40$ & 0.00 \\
\hline Amount received from the utility & (\$/year) & 866.40 & 625.11 & 0.00 \\
\hline Reduction in energy consumption from the electrical utility & $(\mathrm{kWh} /$ year $)$ & $13,274.40$ & $13,274.40$ & $13,274.40$ \\
\hline Saved on energy bill & (\$/year) & $3,982.30$ & $3,982.30$ & $3,982.30$ \\
\hline PV participation in the microgrid & $(\mathrm{kWh} /$ year $)$ & $14,374.30$ & $15,982.40$ & $20,150.30$ \\
\hline
\end{tabular}

The average values received during a year for each owner of a photovoltaic generator are shown in Table 8.

Table 8. Average annual values received by each owner of a generation system.

\begin{tabular}{cccc}
\hline Description & Topology 1 (\$/year) & Topology 2 (\$/year) & Topology 3 (\$/year) \\
\hline Amount received from members of the microgrid & 24.75 & 60.94 & 154.71 \\
Amount received from the utility & 86.64 & 62.51 & 0.00 \\
Saved on energy bill & 398.21 & 398.21 & 398.21 \\
Total revenue & 509.60 & 521.66 & 552.92 \\
\hline
\end{tabular}

The net present value (NPV) and internal rate of return (IRR) were analyzed for each topology. The results are shown in Table 9.

The analysis shows that the studied systems are not economically feasible when the energy prices currently in effect are considered. However, the microgrid system is more economically attractive than a system without a microgrid, although economic viability has not been achieved in either case. 
In other words, a microgrid is an alternative to improve the economic feasibility of photovoltaic systems with and without energy storage.

Table 9. Net present value (NPV) and internal rate of return (IRR) for the topologies analyzed.

\begin{tabular}{cccc}
\hline Variables & Topology $\mathbf{1}$ & Topology 2 & Topology 3 \\
\hline NPV (\$) & -7779.28 & -7436.47 & -6508.99 \\
IRR (\%) & -2.15 & -1.95 & -1.44 \\
\hline
\end{tabular}

In the proposed system, energy storage accounts for approximately $18 \%$ of the total costs, and the cycle of charging and discharging a battery requires extra energy effort. Energy storage capability is a good option when there is a need for energy independence and in the case of time of use tariffs, where the peak rates are much greater then off peak rates. Thus, in the case of flat tariffs, when energy independence is not a concern, feasibility should be achieved more easily.

\subsection{Cost Reduction of Generators and Equipment}

Net present values (NPV) and internal rate of return (IRR) for the three topologies were carried out considering technology cost reductions of $20 \%, 40 \%$ and $60 \%$. The results are shown in Table 10 .

Table 10. Net present values (NPV) and internal rate of return (IRR) for the three topologies considering equipment cost reductions of $20 \%, 40 \%$ and $60 \%$.

\begin{tabular}{ccccc}
\hline Economic Indicators & Reduction & Topology 1 & Topology 2 & Topology 3 \\
\hline NPV (\$) & \multirow{2}{*}{$20 \%$} & -4304.64 & -3943.33 & -3015.85 \\
IRR (\%) & & -1.07 & -0.82 & -0.21 \\
\hline NPV (\$) & \multirow{2}{*}{$40 \%$} & 1354.40 & 1712.22 & 2639.69 \\
IRR (\%) & \multirow{2}{*}{$60 \%$} & 2.46 & 2.68 & 3.25 \\
\hline NPV (\$) & \multirow{2}{*}{6042.82} & 6300.63 & 7228.11 \\
IRR (\%) & & 6.63 & 6.89 & 7.55 \\
\hline
\end{tabular}

The results presented in Table 10 show that the investment becomes feasible when there is an approximately $40 \%$ reduction in the initial costs of PV system installation, and greater financial return occurs in topology 3. A $40 \%$ reduction in current prices provides $\$ 6.00$ per $\mathrm{W}$, the same price for system feasibility found by [18] for Japan. This reduction in the prices of photovoltaic generators and other equipment necessary for system operation can be achieved if there is a substantial market expansion of photovoltaic panels, which is expected in the near future.

\subsection{Increase in Energy Prices above Inflation}

The second sensitivity analysis addressed the effect of energy price variation increases above inflation. The results are shown in Table 11. 
Table 11. Effect of variation in the annual increase in energy prices above inflation.

\begin{tabular}{ccccc}
\hline Economic Indicators & Annual Energy Price Variation above Inflation & Topology 1 & Topology 2 & Topology 3 \\
\hline NPV (\$) & \multirow{2}{*}{$0 \%$} & $-12,633.71$ & $-12,389.76$ & $-11,757.42$ \\
IRR (\%) & \multirow{2}{*}{$1 \%$} & - & - & - \\
\hline NPV (\$) & \multirow{2}{*}{$\%$} & $-11,274.30$ & $-10,998.17$ & $-10,282.44$ \\
IRR (\%) & & - & - & - \\
\hline NPV (\$) & \multirow{2}{*}{$3 \%$} & $-9,684.73$ & $-9,370.98$ & $-8,557.75$ \\
IRR (\%) & & - & - & - \\
\hline NPV (\$) & \multirow{2}{*}{$4 \%$} & $-7,822.43$ & $-7,464.61$ & $-6,537.14$ \\
IRR (\%) & \multirow{2}{*}{$5 \%$} & -2.16 & -1.96 & -1.45 \\
\hline NPV (\$) & \multirow{2}{*}{$\%$} & $-5,636.75$ & $-5,227.21$ & $-4,165.66$ \\
IRR (\%) & & -0.88 & -0.68 & -0.18 \\
\hline NPV (\$) & & 0.367 .48 & $-2,597.14$ & $-1,377.99$ \\
IRR (\%) & & & 0.55 & 1.04 \\
\hline
\end{tabular}

The results show that with current equipment prices needed to install the system, the viability of the investment cannot be achieved by considering up to a 5\% increase in energy prices above inflation.

System without Energy Storage

In the fourth current analysis, PV systems without energy storage were considered. The net present values (NPV) and internal rate of return (IRR) for this case are shown in Table 12.

Table 12. Net present values (NPV) and internal rate of return (IRR) for the three topologies for a system without energy storage.

\begin{tabular}{cccc}
\hline Economic Indicators & Topology $\mathbf{1}$ & Topology 2 & Topology 3 \\
\hline NPV (\$) & -2491.64 & -1068.83 & 2619.25 \\
IRR (\%) & 0.23 & 1.02 & 2.83 \\
\hline
\end{tabular}

In the system without energy storage and with the present energy prices, only systems implemented with topology 3 are feasible. It is important to observe that, in a system without storage, the availability of energy generated by the PV system occurs only when there is solar radiation. In this situation, the system owner would probably try to adjust the load curve to utilize the available power. In doing so, the financial return would be higher because instead of selling energy for $\$ 0.22 / \mathrm{kWh}$ to the energy company, the owner would avoid buying it for $\$ 0.30 / \mathrm{kWh}$. Without energy storage, the initial expenditures on batteries and battery replacement every ten years are completely eliminated, contributing significantly to the feasibility of the investment. Reference [16] showed that in Italy PV systems without energy storage that are connected to the grid are economically feasible for all simulated scenarios, and the discounted payback period is approximately 14 years. The results differ from the results of this study because of the higher cost of PV modules in Brazil. 


\subsection{Variation in the Cost of Surplus Energy Sales}

The fifth analysis presented in this work considered the variation of the energy surplus selling value. Most feed-in tariff programs encourage the use of renewable sources buying energy excess for a price higher than that of conventional energy. The considered variation in the cost of surplus energy sales ranges between $\$ 0.22 / \mathrm{kWh}$ and $\$ 0.33 / \mathrm{kWh}$. The results are shown in Table 13 .

Table 13. Analysis of the variation in the selling price of surplus energy to the electrical energy utility of one microgrid participant $(\$ / \mathrm{kWh})$.

\begin{tabular}{ccccc}
\hline Economic Indicator & Selling Price $\mathbf{( \$ / k W h )}$ & Topology 1 & Topology 2 & Topology 3 \\
\hline NPV (\$) & \multirow{2}{*}{0.22} & -6543.37 & -6537.73 & -6508.99 \\
IRR (\%) & & -1.46 & -1.46 & -1.44 \\
\hline NPV (\$) & \multirow{2}{*}{0.27} & -5687.89 & -5919.61 & -6508.99 \\
IRR (\%) & \multirow{2}{*}{0.33} & -1.01 & -1.13 & -1.44 \\
\hline NPV (\$) & \multirow{2}{*}{0.4832 .42} & -5301.49 & -6508.99 \\
IRR (\%) & & -0.58 & -0.82 & -1.44 \\
\hline
\end{tabular}

The results show that even if the utility pays $10 \%$ more than the current price of energy, the proposed microgrid is not economically viable. Simulations with higher prices would lead to a favorable condition, but these scenarios are unlikely to occur. In Reference [18], it is found that $\$ 0.23 / \mathrm{kWh}$ is adequate to reach economic feasibility in Japan.

\subsection{Labeling of Buildings}

Some countries have already developed a process to evaluate buildings on energy usage efficiency. The buildings evaluated receive a rating label that influences the value of the property. The use of renewable energy sources is a positive factor in building evaluations. In Brazil, this type of classification has recently started to be used in commercial buildings. When such ratings reach households, labeling will become an important variable in the calculation of the financial return of photovoltaic systems and may improve it considerably.

\subsection{Power Supply at Peak Hours}

Another important factor to be considered is the use of photovoltaic energy in peak periods. With gradual replacement of conventional meters for electricity consumption by electronic meters, the price of $1 \mathrm{kWh}$ will depend on the usage time period. Because energy at peak hours may cost eight to twelve times the off-peak energy, the savings achieved with this process can be greater than the values used in the economic analysis presented previously, resulting in increased financial return of the investment. The benefits of a microgrid when considering time-of-use energy pricing are discussed by [19]. The batteries' SOC can be controlled, allowing discharging in peak hours and recharging in off-peak periods. This control benefits the consumer, who will pay for cheaper energy, and the grid, by reducing the load curve on demand peak hours. In Brazilian urban areas, demand peak and photovoltaic energy generation coincide because of large air-conditioning systems [20], making PV energy a natural choice for supplying this demand. 


\subsection{Access to Temporary Energy Contract}

According to current legislation in Brazil, consumers served at voltage levels ranging from 2.3 to $230 \mathrm{kV}$, with energy backup systems, are eligible to gain access to temporary energy contracts. Such contracts allow, for a given period of time, low cost electrical energy with the same reliability as long-run contracts. With this type of supply, the price of electrical energy from the grid is reduced because the market has an energy surplus at present, which can increase the return of the investment in photovoltaic generators.

\subsection{Possibility of Legislation}

Potential government incentives for photovoltaic electrical energy generation were not taken into account in analyses performed in this work, which would contribute to the feasibility of implementing such systems. These incentives could take the form of, for example, reduced energy tariffs or lending for the purchase of equipment, with a consequent market increase.

There are examples to be studied and adapted to the case of Brazil. The most prominent is the German model for encouraging the use of photovoltaic energy. In Germany, residential consumers can have their own power generation and sell it to the energy company, which is required by law to purchase all energy available at a price higher than the conventional. The cost of the PV energy is prorated to other consumers.

A procedure similar to that of Germany for electricity generation occurs in remote areas in Brazil, using diesel generators. The cost of operating these systems is prorated to consumers in other regions. Thus, those who need diesel do not pay the same cost as those in regions connected to conventional grid, which is mainly hydroelectric.

With the creation and expansion of the photovoltaic market in Brazil and the probable consequent cost reductions, solar PV energy would become attractive to residential consumers. Market creation depends on government incentives similar to those of the German program, in which the utility is required to buy all electrical energy surplus coming from renewable sources at a rate higher than the conventional price. ANEEL Normative Resolution 482, published in April 2012, which allows consumers to install small generation units in their homes, is the first step to expand the PV market in Brazil [21]. Other factors, including the relevance of energy independence and the cost of a lack of energy when the conventional grid fails, are more difficult to evaluate, but they must be considered for a better analysis.

\section{Conclusions}

The elevated costs of PV modules currently prevent PV system feasibility in Brazil. This paper presented some factors that affect the feasibility of microgrids, for both participants with and without photovoltaics and energy storage systems. The analysis results showed that the proposed microgrid can provide economic feasibility in some cases, giving a return of investment for a system that would be a financial loss if it were simply installed in a house and connected to the grid. According to the sensitivity analysis, the reduction of PV module prices must be the main goal in Brazil to promote the feasibility of PV systems. The systems feasibility would also be improved with higher efficiency of the inverters and the energy storage systems and the planned adoption of the time-of-use electrical energy tariffs. 
The price of PV modules have dropped systematically and the adoption of these systems in a large scale in Brazil can force down the microgrid component prices, as has happened in countries that choose to invest in PV systems. Additionally, the energy price in Brazil has been increased in recent years because of non-favorable climatic conditions that made the hydroelectric power stations reservoirs fall to a very low level, as never seen before. Facing this scenario, the power management players had to activate all the thermal power plants which generate energy at very expensive rates in Brazil. As shown in the performed analysis, higher energy prices are favorable to the PV systems deployment.

Although the sensitivity analysis showed a range of simulation results, several other factors not yet measured can be combined to make the use of photovoltaic power generation a feasible alternative for residential consumers. The factors not yet measured include the following: (I) building labeling; (II) environmental concerns; (III) health due to avoided emissions; (IV) promotion of energy independency; and (V) decrease of fuel import, in the case of many countries.

Regulatory issues and techniques still need to be improved in Brazil, which will demand further discussions. The microgrid model proposed in this study cannot be implemented in Brazil at present because of legal issues regarding energy trading, only utilities can trade electricity. Prior to the implementation of microgrids in Brazil, it is necessary to discuss and formalize technical issues related to the electrical connection among a group of consumers and the utility.

Although the limited number of the microgrid participants used in the simulations, some conclusions can be extended to a higher penetration level of distributed photovoltaic energy. The analyses showed a tendency of an improved NPV for larger microgrid systems. The microgrid planner's ability to overcome the issues of larger systems and the development of higher performance microgrid components may contribute to make it profitable to the investors.

\section{Acknowledgments}

The authors are grateful for the financial support provided by National Council for Scientific and Technological Development (CNPq), Research Support Foundation of Minas Gerais (FAPEMIG) and Higher Education Personnel Training Coordination (CAPES), as well as the Universidade Federal de Viçosa, for the opportunity given.

\section{Author Contributions}

This paper is part of the first author's research conducted at the Universidade Federal de Viçosa, Viçosa, Minas Gerais, Brazil. This research was supervised, and co-supervised by the corresponding author and the remaining authors, respectively.

\section{Conflicts of Interest}

The authors declare no conflict of interest. 


\section{References}

1. Lasseter, R.; Akhil, A.; Marnay, C.; Stevens, J.; Dagle, J.; Guttromson, R.; Meliopoulous, A.S.; Yinger, R.; Eto, J. White Paper on Integration of Distributed Energy Resources: The CERTS Microgrid Concept; Berkeley Lab Report; University of California: Berkeley, CA, USA, 2002; p. 46.

2. Diniz, A.S.A.C.; Machado Neto, L.V.B.; Camara, C.F.; Morais, P.; Cabral, C.V.T.; Oliveira Filho, D.; Ravinetti, R.F.; Franc, E.D.; Cassini, D.A.; Souza, M.E.M.; et al. Review of the photovoltaic energy program in the state of Minas Gerais, Brazil. Renew. Sustain. Energy Rev. 2011, 15, 2696-2706.

3. ANEEL. Brazilian Electricity Regulatory Agency-Generation Database. Available online: http://www.aneel.gov.br/area.cfm?id_area=15 (accessed on 1 June 2010). (In Portuguese)

4. Pao, H.T.; Fu, H.C. Renewable energy, non-renewable energy and economic growth in Brazil. Renew. Sustain. Energy Rev. 2013, 25, 381-392.

5. Energy Research Company Brazilian Energy Balance; Ministry of Mines and Energy: Rio de Janeiro, Brazil, 2011.

6. Lasseter, R.H. Microgrids and distributed generation. J. Energy Eng. Am. Soc. Civil Eng. 2007, $133,144-149$.

7. Huang, J.; Jiang, C.; Xu, R. A review on distributed energy resources and microgrid. Renew. Sustain. Energy Rev. 2008, 12, 2472-2483.

8. Varella, F.K.O.M.; Cavaliero, C.K.N.; Silva, E.P. Energia solar fotovoltaica no Brasil: Incentivos regulatórios. Rev. Bras. Energ. 2008, 14, 9-22. (In Portuguese)

9. Toledo, O.M.; Oliveira Filho, D.; Diniz, A.S.A.C. Distributed photovoltaic generation and energy storage systems: A review. Renew. Sustain. Energy Rev. 2010, 14, 506-511.

10. Rüther, R.; Knob, P.J.; Jardim, C.S.; Rebechi, S.H. Potential of building integrated photovoltaic solar energy generators in assisting daytime peaking feeders in urban areas in Brazil. Energy Convers. Manag. 2008, 49, 1074-1079.

11. Cabral, C.V.T.; Oliveira Filho, D.; Diniz, A.S.A.C.; Martins, J.H.; Toledo, O.M.; Machado Neto, L.V.B. A stochastic method for stand-alone photovoltaic system sizing. Sol. Energy 2010, 84, 1628-1636.

12. Procel-National Program of Electric Energy Conservation. Available online: http://www.procelinfo. com.br/main.asp (accessed on 30 May 2011). (In Portuguese)

13. Souza, A.N.; Costa Junior, P.; Oliveira, R.; Zago, M.G.; Papa, J.P.; Gastadello, D.S. Algoritmos para estimar curvas de carga a partir de padrões de hábitos de consumo. In Proceedings of the 9th Brazilian Conference on Dynamics, Control and their Applications, Serra Negra, Brazil, 7-11 July 2010. (In Portuguese)

14. Grupo de Trabalho de Energia Solar-GTES; CEPEL_DTE—CRESESB. Manual de Engenharia Para Sistemas Fotovoltaicos. Available online: http://www.cresesb.cepel.br/publicacoes/ download/Manual_de_Engenharia_FV_2014.pdf (accessed on 22 February 2015).

15. General Sizing Instructions; Sandia National Lab: Springfield, VA, USA, 2009.

16. Cucchiella, F.; D’Adamo, I.; Gastaldi, M.; Koh, S.C.L. Renewable energy options for buildings: Performance evaluations of integrated photovoltaic systems. Energy Build. 2012, 55, 208-217. 
17. Talavera, D.L.; Muñoz-Cerón, E.; Casa, J.; Ortega, M.J.; Almonacid, G. Energy and economic analysis for large-scale integration of small photovoltaic systems in buildings: The case of a public location in Southern Spain. Renew. Sustain. Energy Rev. 2011, 15, 4310-4319.

18. Ren, H.; Gao, W.; Ruan, Y. Economic optimization and sensitivity analysis of photovoltaic system in residential buildings. Renew. Energy 2009, 34, 883-889.

19. Sechilariu, M.; Wang, B.; Locment, F. Building-integrated microgrid: Advanced local energy management for forthcoming smart power grid communication. Energy Build. 2013, 59, 236-243.

20. Jardim, C.S.; Rüther, R.; Salamoni, I.T.; Viana, T.S.; Rebechi, S.H.; Knob, P.J. The strategic siting and the roofing area requirements of building-integrated photovoltaic solar energy generators in urban areas in Brazil. Energy Build. 2008, 40, 365-370.

21. ANEEL. Brazilian Electricity Regulatory Agency. Resolução Normativa no. 482, de 17 de Abril de 2012. Available online: http://www.aneel.gov.br/cedoc/ren2012482.pdf (accessed on 22 February 2015). (In Portuguese)

(C) 2015 by the authors; licensee MDPI, Basel, Switzerland. This article is an open access article distributed under the terms and conditions of the Creative Commons Attribution license (http://creativecommons.org/licenses/by/4.0/). 